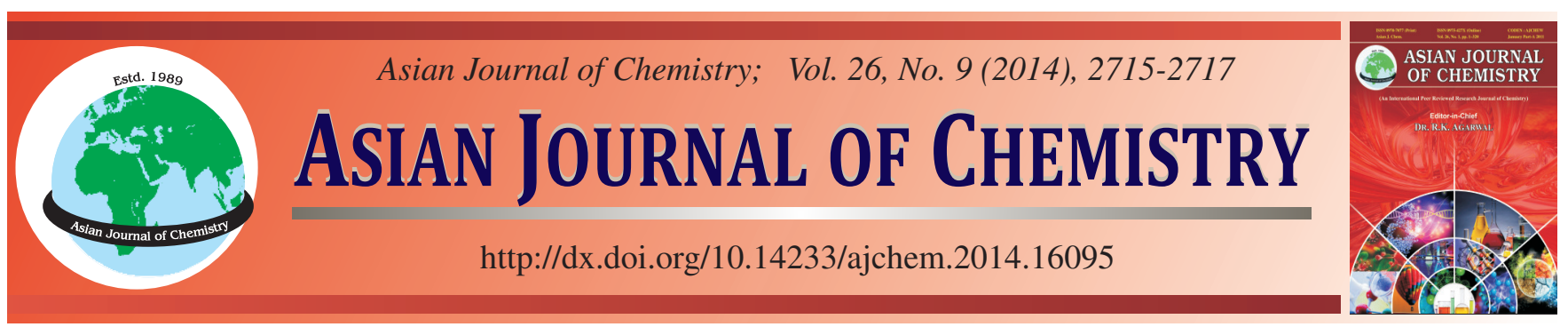

\title{
Crystal Structure of 3-Chloromethyl-(3-phenyl-oxiranyl)phenyl Methanone: New Monoclinic Polymorph
}

\author{
Muhammad Nadeem Arshad ${ }^{1,2, *}$, Abdullah M. Asiri ${ }^{1,2}$, Khalid A. Alamry ${ }^{1}$, Salih S. Al-Juaid ${ }^{1}$, \\ Sher Bahadar Khan ${ }^{1,2}$, TAnveer Hussain Bokhari ${ }^{3}$ and Muhammad ShafiQ ${ }^{3}$
}

${ }^{1}$ Chemistry Department, King Abdulaziz University, Jeddah 21589, Saudi Arabia

${ }^{2}$ Center of Excellence for Advanced Materials Research (CEAMR), King Abdulaziz University, Jeddah 21589 Saudi Arabia

${ }^{3}$ Department of Chemistry, Government College University Faisalabad, Faisalabad, Pakistan

*Corresponding author: Tel: +966 580330428, E-mail: mnachemist@ hotmail.com

Received: 24 July 2013;

Accepted: 6 December 2013;

Published online: 28 April 2014;

AJC-15104

The compound, 3-chloromethyl-(3-phenyl-oxiranyl)phenyl methanone [m.f. $\mathrm{C}_{16} \mathrm{H}_{13} \mathrm{O}_{2} \mathrm{Cl}$ ] was a self-condensation product of phenacyl chloride where the reaction carried out in ethanol medium using inorganic base. This was crystalized in monoclinic with space group $\mathrm{P} 2_{1} / \mathrm{c}$ (no. 14), $\mathrm{a}=10.1312$ (2) $\AA, \mathrm{b}=11.7728 \AA, \mathrm{c}=11.8566 \AA, \mathrm{V}=1344.07 \AA 3, \mathrm{Z}=4$ and $\rho_{\text {calc. }}=1.348 \mathrm{mg} / \mathrm{mm}^{3}$. The dihedral angle between two aromatic rings is $73.46(5)$. The epoxide ring is oriented at dihedral angles of $62.12\left(9^{\circ}\right)$ and $60.87\left(7^{\circ}\right)$ with respect to the phenyl and benzoyl rings. The non-classical intermolecular hydrogen bonding of $\mathrm{C}-\mathrm{H} \cdots \mathrm{O}$ type has been observed in the crystal structure of molecule.

Keywords: 3-Chloromethyl-3-phenyl-oxiranyl)phenyl methanone, Crystal structure, New polymorph.

\section{INTRODUCTION}

The C-C bond formation is always been well known chemistry for the preparation of new organic compounds with novel various properties. Darzens' reaction is also one of them which used for $\mathrm{C}-\mathrm{C}$ bond formation in synthetic branch of organic chemistry $^{1,2}$. This reaction also allows to prepare $\alpha, \beta$-epoxy carbonyl derivatives with new stereocenters via diastereocontrol mechanism. These condensation reactions are carried out in the presence of strong base while organic solvents usually used as medium ${ }^{3}$. In order to meet the modern methodologies for betterment of environment and more socio-economic benefits phase transfer catalyst (PTC) have also been applied as catalyst ${ }^{4-6}$. Wang et $a l^{7}$ reported the Darzens condensation reaction of ethyl acetate with different aldehydes using newly synthesized polystyrene-based quaternary ammonium compounds as catalysts. The pharmaceutical significance (synthesis of diltiazem; a blood pressure lowering drug) of Darzens reactions vindicates the special consideration of researchers ${ }^{8,9}$. The epoxy ketones, both in their racemic as well as optically active forms are considered as useful building blocks for the synthesis of various organic compounds ${ }^{10}$. The two active functionalities (keto and epoxy) can be further derivatized to yield potential intermediates of natural, industrial and biologically active compounds ${ }^{11-13}$. The title compound i.e., 3-chloromethyl-(3-phenyl-oxiranyl)phenyl

methanone is also epoxy ketone and synthesized via selfcondensation of phenacyl chloride in the presence of sodium hydroxide as base and crystalized in ethanol under slow evaporation, Scheme-I. The crystal structure is being reported here as another monoclinic polymorph of 3-chloromethyl-(3-phenyloxiranyl)phenyl methanone.<smiles>CCC(=O)c1ccccc1</smiles>

1

Scheme-I: Synthesis of 3-chloromethyl-(3-phenyl-oxiranyl)phenyl methanone (2)

\section{EXPERIMENTAL}

The phenacyl chloride ( $1 \mathrm{~g}, 6.47 \mathrm{mmol})$ was added to aqueous ethanolic solution $(1: 1)$ of sodium hydroxide $(0.52 \mathrm{~g}$, $12.93 \mathrm{mmol}$ ) and the mixture was allowed to stir at room temperature for $2 \mathrm{~h}$. The precipitate obtained was filtered off, washed with cold water and recrystallized in ethanol under slow evaporation to obtain a suitable crystal for X-ray diffraction studies. The ${ }^{1} \mathrm{H}$ NMR was recordede on Bruker Avance $600 \mathrm{MHz}$ spectrometer (Bruker, Germany), in $\mathrm{CDCl}_{3}$ as solvent. The values 
of proton are reported as chemical shifts $(\delta, \mathrm{ppm})$ along-with their multiplicity ( $\mathrm{s}$, singlet; $\mathrm{d}$, doublet; $\mathrm{t}$, triplet; q quartet) relative to the residual $\mathrm{CDCl}_{3}(7.26 \mathrm{ppm})$. The melting point was recorded on Stuart scientific SMP3 (Bibby, UK) melting point apparatus and is reported as uncorrected.

${ }^{1} \mathbf{H}$ NMR (600 MHz) $\left(\mathbf{C D C l}_{3}\right)$ ): 7.89 (2H, d, aromatic), 7.57 (1H, t, aromatic), 7.40 (2H, t, aromatic), $7.35(2 \mathrm{H}, \mathrm{q}$, aromatic), $7.22(2 \mathrm{H}, \mathrm{d}$, aromatic), 7.21 (1H, d, aromatic), $4.65(1 \mathrm{H}, \mathrm{s}, \mathrm{CH})$, $4.08\left(2 \mathrm{H}, \mathrm{s}, \mathrm{CH}_{2}\right)$. m.p. $152-153{ }^{\circ} \mathrm{C}$.

Crystallization of compound $\mathbf{2}$ in ethanol under slow evaporation gave colorless, block type crystals. A suitable crystal was selected and mounted on an Agilent Super Nova Atlas Dual Source, Agilent Technologies diffractometer using the Crys Alis Pro software ${ }^{14}$. The crystal was kept at 296 K during data collection. Using Xseed ${ }^{15}$, the structure was solved with the ShelXS ${ }^{16}$ structure solution program using direct methods and refined with the ShelXL ${ }^{16}$ refinement package using least squares minimization. All the hydrogen atoms were positioned geome-trically with $\mathrm{dC}_{\text {aromatic }}-\mathrm{H}=0.93 \AA, \mathrm{dC}_{\text {chiral }}-\mathrm{H}=0.97 \AA$ $\& \mathrm{dC}_{\text {methylene }}-\mathrm{H}=0.98 \AA$ and were refined using a riding model with $\mathrm{U}_{\text {iso }}(\mathrm{H})=1.2 \mathrm{U}_{\mathrm{eq}}(\mathrm{C})$. The figures were drawn with the help of PLATON ${ }^{17}$ using WinGX ${ }^{18}$. The crystal data was deposited at the Cambridge Crystallographic Data Centre and it has been assigned the deposition number as CCDC 940725. This data can be obtained free of charge from The Cambridge Crystallographic Data Centre via www.ccdc.cam.ac.uk/data_request/ cif.

\section{RESULTS AND DISCUSSION}

The title compound was synthesized through a simple selfcondensation using inorganic base and recrystallized in ethanol as a new monoclinic polymorph. The cambridge structural database $(\mathrm{CSD})^{19}$ speaks about two other polymorphs ${ }^{20}$ with codes QECFAF and QECFEJ. The spectroscopic and crystallographic studies were taken out for the characterization of product. According to the ${ }^{1} \mathrm{H}$ NMR spectra of molecule it is clear that the hydrogen atoms of the benzoyl rings appear in the downfield region $[7.89(2 \mathrm{H}, \mathrm{d}$, aromatic $), 7.57(1 \mathrm{H}, \mathrm{t}$, aromatic), 7.40 (2H, t, aromatic)] due to the de-shielding effect of carbonyl group. On the other hand, five hydrogen atoms of phenyl ring are appeared at $7.35(2 \mathrm{H}, \mathrm{dd}$, aromatic $), 7.22(2 \mathrm{H}$, $\mathrm{d}$, aromatic) and $7.21(1 \mathrm{H}, \mathrm{dd}$, aromatic). The singlet peak of the hydrogen atom attached to chiral carbon $\mathrm{C}_{2}$ appeared at 4.65 while the two hydrogen atoms of methylene $\mathrm{CH}_{2}$ group appeared at 4.08. The Table-1 contains the detail of the crystal data, data collection and structure refinements. Selected bond lengths and bond angles are provided in Tables 2 and 3, respectively. The ORTEP diagram of molecule 2 is shown in Fig. 2, it reveals that the molecule contain two aromatic rings (C4---C9) \& (C10---C15) with root mean square (r.m.s) deviation of 0.0018 (1) $\AA$ \& 0.0033 (1) $\AA$ of the planes produced from their atoms respectively. The oxirane ring $(\mathrm{C} 1 / \mathrm{C} 2 / \mathrm{O} 2)$ is exactly planer with $0.000 \AA$ r.m.s. deviation of its fitted. The three bond angles produced from fitted atoms are $62.78\left(8^{\circ}\right)$, $58.39\left(8^{\circ}\right)$ and $58.82\left(8^{\circ}\right)$.

The dihedral angle between the plane produce through the bonded atoms of two aromatic rings is $73.46\left(5^{\circ}\right)$. The eoxirane ring is oriented at dihedral angle of $62.12\left(9^{\circ}\right)$ and
TABLE-1

CRYSTAL DATA AND STRUCTURE REFINEMENT FOR 2

\begin{tabular}{cc}
\hline Empirical formula & $\mathrm{C}_{16} \mathrm{H}_{13} \mathrm{O}_{2} \mathrm{Cl}$ \\
Formula weight & 272.71 \\
Temperature $(\mathrm{K})$ & 296.15 \\
Crystal System & monoclinic \\
Space group & $\mathrm{P} 2_{1} / \mathrm{c}$ \\
$\alpha(\AA)$ & $10.1312(2)$ \\
$\beta(\AA)$ & $11.7728(2)$ \\
$\mathrm{c}(\AA)$ & $11.8566(3)$ \\
$\beta\left({ }^{\circ}\right)$ & $108.116(3)$ \\
Volume $\left(\AA^{3}\right)$ & $1344.07(5)$ \\
$\mathrm{Z}$ & 4 \\
$\rho_{\text {calc }} \mathrm{mg}\left(\mathrm{mm}^{3}\right)$ & 1.348 \\
$\mathrm{~F}(000)$ & 568.0 \\
Crystal size $\left(\mathrm{mm}^{3}\right)$ & $0.48 \times 0.17 \times 0.08$ \\
$2 \theta$ range for data collection & 9.18 to $152.72^{\circ}$ \\
Index ranges $(\mathrm{h}, \mathrm{k}, \mathrm{l})$ & $-11 \leq \mathrm{h} \leq 12,-14 \leq \mathrm{k} \leq 14,-14 \leq \mathrm{l} \leq 12$ \\
Reflectioned collected & 12607 \\
Independent reflections & $2789[\mathrm{R}(\mathrm{int})=0.0355]$ \\
Data/restraints/parameters & $2789 / 0 / 173$ \\
Goodness-of-fit on $\mathrm{F}^{2}$ & 1.053 \\
Final $\mathrm{R}$ indexes $[\mathrm{I}>=2 \sigma(\mathrm{I})]$ & $\mathrm{R}_{1}=0.0353, \mathrm{wR}_{2}=0.0967$ \\
Final R indexes $[\mathrm{I}>=2 \sigma(\mathrm{I})]$ & $\mathrm{R}_{1}=0.0392, \mathrm{wR} \mathrm{R}_{2}=0.1014$ \\
Largest diff. peak/hole $/ \mathrm{e} \AA^{-3}$ & $0.20 /-0.26$ \\
\hline
\end{tabular}

\begin{tabular}{ccc}
\multicolumn{4}{c}{ TABLE-2 } \\
\multicolumn{4}{c}{ SELECTED BOND LENGTHS OF COMPOUND 2 } \\
\hline Atom & Atom & Length $(\AA)$ \\
\hline C11 & C16 & $1.7886(15)$ \\
O1 & C1 & $1.4349(15)$ \\
O1 & C2 & $1.4284(17)$ \\
O2 & C3 & $1.2162(17)$ \\
C1 & C2 & $1.4914(19)$ \\
C1 & C10 & $1.4955(19)$ \\
C1 & C16 & $1.504(2)$ \\
C2 & C3 & $1.500(2)$ \\
C3 & C4 & $1.4821(19)$ \\
C4 & C5 & $1.390(2)$ \\
C4 & C9 & $1.386(2)$ \\
\hline
\end{tabular}

\begin{tabular}{cccc}
\multicolumn{5}{c}{ TABLE-3 } \\
\multicolumn{5}{c}{ SELECTED BOND ANGLES OF COMPOUND 2 } \\
\hline Atom & Atom & Atom & Angle $\left({ }^{\circ}\right)$ \\
\hline C2 & O1 & C1 & $62.78(8)$ \\
O1 & C1 & C2 & $58.39(8)$ \\
O1 & C1 & C10 & $115.42(11)$ \\
O1 & C1 & C16 & $114.29(11)$ \\
C2 & C1 & C10 & $120.77(11)$ \\
C2 & C1 & C16 & $115.83(12)$ \\
C10 & C1 & C16 & $117.96(11)$ \\
O1 & C2 & C1 & $58.82(8)$ \\
O1 & C2 & C3 & $117.50(12)$ \\
C1 & C2 & C3 & $120.21(12)$ \\
O2 & C3 & C2 & $120.60(13)$ \\
O2 & C3 & C4 & $121.99(13)$ \\
C4 & C3 & C2 & $117.42(12)$ \\
C5 & C4 & C3 & $123.09(13)$ \\
C 9 & C4 & C3 & $118.23(13)$ \\
\hline
\end{tabular}

$60.87\left(7^{\circ}\right)$ with respect to the phenyl (C10---C15) and benzoyl (C4---C9) rings. The non-classical C---H...O type intermolecular hydrogen bonding have also been observed in the molecule which may help to stabilize the crystal structure of molecule Fig. 3 and Table-4. This interaction connects the molecules along $c$-axes to make an infinite chain. 


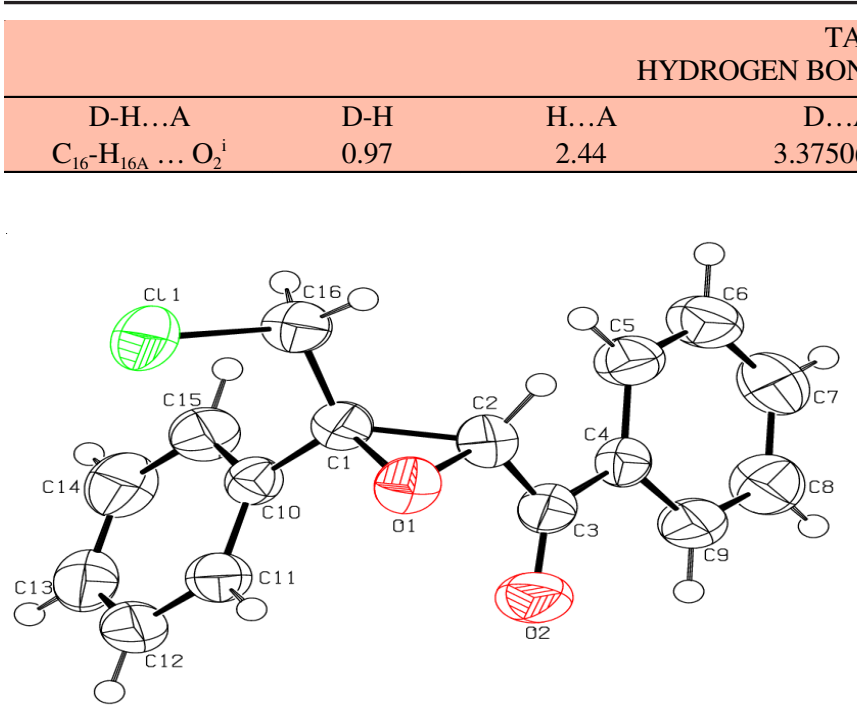

Fig. 2. ORTEP diagram of compound 2 drawn at $50 \%$ probability of thermal ellipsoid

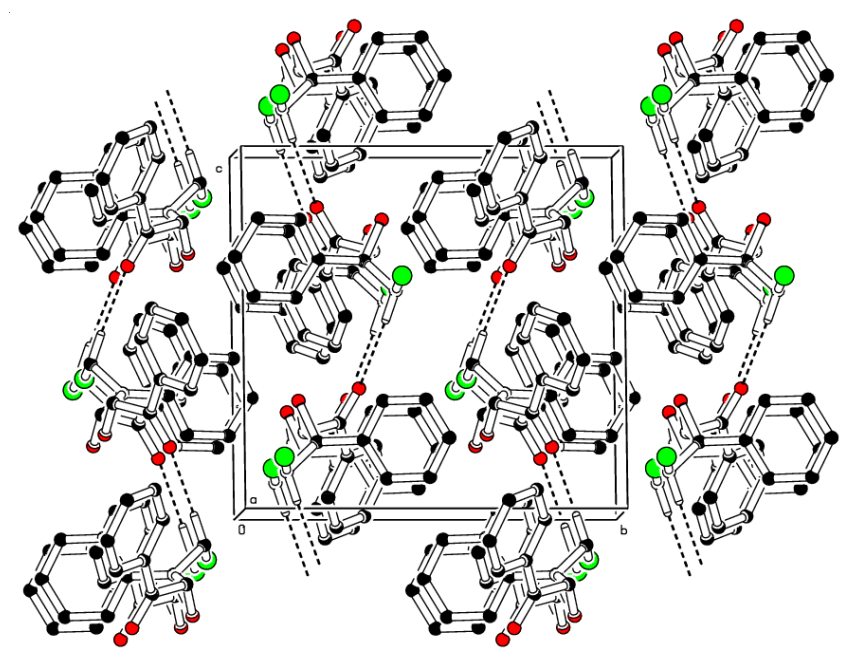

Fig. 3. Unit cell packing of compound $\mathbf{2}$ showing the hydrogen bonding using dashed lines, all other hydrogen atoms not involved in hydrogen bonding have been omitted for clarity
TABLE-4

OND GEOMETRY $\left(\AA,^{\circ}\right)$

D-H...A

160.6

Symmetry code / symmetry operation $4 \_565 /{ }^{\mathrm{X} X}, 1 / 2-\mathrm{Y}, \mathrm{Z}-1 / 2$

\section{ACKNOWLEDGEMENTS}

This project was funded by the Deanship of Scientific Research (DSR), King Abdulaziz University, Jeddah, under grant no. (169/130/1433). The authors, therefore, acknowledged with thanks DSR technical and financial support.

\section{REFERENCES}

1. R.O.C. Norman and C.M. Coxon, Principles of Organic Synthesis, CRC Press, New York (2009).

2. R. Noyori, Asymmetric Catalysis in Organic Synthesis, John Wiley \& Sons, New York (1994).

3. F.W. Bachelor and R.K. Bansal, J. Org. Chem., 34, 3600 (1969).

4. R.K. Boeckman Jr., T.J. Clark and B.C. Shook, Helv. Chim. Acta, 85, 4532 (2002).

5. A. Jonczyk and K. Michalski, Synlett, 1703 (2002).

6. L.W. Xu, J.W. Li, S.L. Zhou and C.G. Xia, New J. Chem., 28, 183 (2004).

7. Z.-T. Wang, L.-W. Xu, C.-G. Xia and H.-Q. Wang, Helv. Chim. Acta, 87, 1958 (2004).

8. O. Miyata, T. Shinada, I. Ninomiya and T. Naito, Tetrahedron, 53, 2421 (1997).

9. B.M. Adger, J.V. Barkley, S. Bergeron, M.W. Cappi, B.E. Flowerdew, M.P. Jackson, R. McCague, T.C. Nugent and S.M. Roberts, J. Chem. Soc., Perkin Trans. I, 3501 (1997).

10. C. Lauret, Tetrahedron Asymm., 12, 2359 (2001).

11. J.R. Flisak, K.J. Gombatz, M.M. Holmes, A.A. Jarmas, I. Lantos, W.L. Mendelson, V.J. Novack, J.J. Remich and L. Snyder, J. Org. Chem., 58, 6247 (1993).

12. P.C. Ray and S.M. Roberts, J. Chem. Soc., Perkin Trans. I, 149 (2001).

13. T. Nemoto, T. Ohshima and M. Shibasaki, Tetrahedron Lett., 41, 9569 (2000).

14. Agilent, CrysAlis PRO, Agilent Technologies, Yarnton, England (2012).

15. L.J. Barbour, J. Supramol. Chem., 1, 189 (2001).

16. G.M. Sheldrick, Acta Crystallogr. A, 64, 112 (2008).

17. A.L. Spek, Acta Crystallogr. D Biol. Crystallogr., 65, 148 (2009).

18. L.J. Farrugia, J. Appl. Cryst., 45, 849 (2012).

19. I.J. Bruno, J.C. Cole, P.R. Edgington, M. Kessler, C.F. Macrae, P. McCabe, J. Pearson and R. Taylor, Acta Crystallogr., B58, 389 (2002).

20. P. Bako, E. Czinege, T. Bako, M. Czugler and L. Toke, Tetrahedron Asymm., 10, 4539 (1999). 